\title{
Kajian Komposisi dan Stratifikasi Tanaman Hortikultura Sebagai Penyusun di Ruang Terbuka Hijau (RTH) Taman Sritanjung Banyuwangi
}

\author{
Tristi Indah Dwi Kurnia ${ }^{1}$, Achmadi Susilo ${ }^{2}$ \\ ${ }^{I}$ Fakultas MIPA, Universitas PGRI Banyuwangi, Jl. Ikan Tongkol no 22, Banyuwangi, 41482 \\ E-mail: tristi.indah@yahoo.com \\ ${ }^{2}$ Fakultas Pertanian, Universitas Wijaya Kusuma Surabaya, Jl. Dukuh Kupang XXV/54, surabaya,60225 \\ E-mail: -
}

\begin{abstract}
The objectives of this study were (1) to determine the composition of the types of horticultural plants used as constituents in the green open space of Taman Sritanjung Banyuwangi and (2) to determine the canopy stratification pattern of horticultural plants in the Green Open Space (GOS) of Taman Sritanjung Banyuwangi. The method of determining the location of the research used is the purposive method, namely GOS Taman Sritanjung Banyuwangi. The research data were obtained by using the line line census method, namely all plants in GOS that followed the line line were used as research samples. The data obtained were analyzed descriptively qualitatively. The results showed that (1) the composition of horticultural plants that make up of GOS consists 33 types of plants with function as shade plant (5 types), absorbers pollutions (4 types), noise absorbing plant (4 types), wind breakers (6 types), plant barrier, guide and form of views (7 types), conservation plant, and cover crops (8 types), and (2) In terms of stratification, horticultural plants selected as constituents in Sritanjung Banyuwangi GOS can be grouped into Emergent Layers, Canopy Layers, Lower Canopy, Shrubs and Ground Cover.
\end{abstract}

Keywords—: Composition; Stratification; GOS.

\section{PENDAHULUAN}

Banyuwangi merupakan salah satu Kota di Ujung timur pulau Jawa yang kini telah menjadi salah satu destinasi wisata dunia. Letak Kota Banyuwangi yang berbatasan langsung dengan Selat Bali ini, menjadi salah satu alasan banyak wisatawan yang akan berlibur ke Bali menyempatkan menikmati wisata di Kota Banyuwangi. Tempat wisata yang dapat dikunjungi di Banyuwangi cukup lengkap, mulai dari Wisata Pegunungan, Wisata Pantai, Wisata Hutan hingga Wisata Ruang Terbuka Hijau yang berada di tengah kota. RTH saat ini kerap kali menjadi salah satu tempat wisata bagi warga perkotaan karena telah dilengkapi dengan tanaman yang bernilai estetika sehingga RTH menjadi tampak indah. Menurut UU RI no 26 Tahun 2007, Pengertian Ruang Terbuka Hijau adalah Ruang yang berfungsi sebagai wadah untuk kehidupan manusia, baik secara individu maupun secara berkelompok serta wadah bagi mahluk hidup lainnya untuk hidup dan berkembang secara berkelanjutan. Ruang Terbuka Hijau secara ekologi dapat menyuguhkan area nyaman melalui tajuk-tajuknya. Tanaman Penyusun RTH adalah Jenis Tanaman Hortikultura khususnya tanaman hias yang sesuai dengan fungsi RTH agar maksimal, baik fungsi utama sebagai penunjang ekologi kehidupan maupun fungsi lain seperti estetika, fungsi sosial dan budaya. (Purwatik et al., 2014)

Tanaman Hortikultura merupakan jenis tanaman yang dibudidayakan dan nantinya dapat dimanfaatkan sebagai sumber Vitamin, mineral, obat-obatan maupun adanya nilai estetika yang dijadikan sebagai tanaman hias. Menurut Balai Penelitian Tanaman Hias (2018), tanaman hias adalah suatu tanaman yang mempunyai nilai keindahan baik bentuk, warna daun, tajuk maupun bunganya yang sering digunakan untuk penghias pekarangan, taman dan ruang hijau.

Pembangunan Ruang Terbuka Hijau (RTH) di suatu daerah ditujukan sebagai ruang ekologi yang dalam penyusunannya perlu memperhatikan komponen Stratifikasi yakni pola penaungan tanaman serta Komposisi jenis tanaman yang akan ditanam didalamnya. Menurut Kershaw (1973) Pola naungan bila ditinjau dari tinggi tegakan tanaman hortikultura dibagi menjadi lima tingkatan yakni Emergent Layer, Canopy Layer, Lower Canopy, Shrubs dan Ground Cover. Kriteria umum dalam penentuan komposisi jenis tanaman yang akan ditanam di suatu RTH menurut Kaharudin (2002) adalah didasarkan fungsi masing masing tanaman sebagai penyusun RTH diantaranya yaitu sebagai penyerap polutan, penyerap debu, peredam kebisingan, penahan angin, peneduh atau pembentuk iklim mikro, fungsi estetika, tanaman produksi dan tanaman kulturasi.

Saat ini, Banyuwangi memiliki tiga RTH yang pembangunannya berada di daerah kota Banyuwangi dan enam lainnya berada di beberapa desa di luar kota Banyuwangi. (Bappeda, 2013) Selama ini RTH yang berada di dalam kota Banyuwangi masih memiliki fungsi dominan yakni sebagai tempat hiburan bagi masyarakat setempat. Masyarakat hanya berkunjung di RTH untuk duduk, bersantai dan berolahraga bersama keluarga, sedangkan fungsi edukasi pada RTH di Banyuwangi masih belum berjalan. 
Website : http://agritek.unmermadiun.ac.id/index.php/agritek

Dengan dilakukannya penelitian ini diharapkan nantinya dapat dijadikan sebagai referensi untuk peningkatan fungsi RTH utamanya fungsi edukasi bagi masyarakat. Kajian Identifikasi Komposisi jenis tanaman hortikultura yang ditanam di RTH Sritanjung Banyuwangi harapannya dapat menjadi salah satu kebijakan bagi Pemkab Banyuwangi untuk memberikan label nama pada setiap tanaman yang ada di sana sehingga masyarakat menjadi lebih kenal dan akrab terhadap nama nama tanaman khususnya tanaman hortikutura yang ada di RTH Sritanjung Banyuwangi.

Rumusan masalah : (1) bagaimanakah komposisi jenis tanaman hortikultura penyusun RTH Taman Sritanjung banyuwangi ? dan (2) Bagaimanakah pola stratifikasi kanopi tanaman hortikuktura pada RTH Sritanjung Banyuwangi ? Tujuan penelitian ini adalah untuk (1) mengetahui komposisi jenis tanaman hortikultura yang digunakan sebagai penyusun di RTH Taman Sritanjung Banyuwangi dan (2) untuk mengetahui pola stratifikasi kanopi dari tanaman Hortikultura di RTH Taman Sritanjung Banyuwangi.

\section{METODE PENELITIAN}

Penelitian dilaksanakan di RTH Taman Sritanjung Banyuwangi yang terletak di jalan Sritanjung Temenggungan Banyuwangi. dengan ketinggian $200 \mathrm{~m}$ di atas permukaan laut dengan suhu harian $31^{\circ} \mathrm{C}$. Penelitian dilakukan pada bulan September - Desember 2020. Penentuan lokasi penelitian menggunakan metode purpossive area yakni RTH Taman Sritanjung Banyuwangi. Data tentang jenis-jenis tanaman pada RTH diamati dengan Metode Sensus jalur garis, yakni seluruh tanaman yang ada di RTH dijadikan sebagai sampel dalam penelitian ini mengikuti jalur garis jalan yang ada di RTH Sritanjung Banyuwangi. Bahan yang digunakan adalah sampel tanaman yang ada di RTH Sritanjung Banyuwangi. Alat-alat yang digunakan adalah Camera, alat tulis, Handphone Android untuk penentuan nama jenis tanaman dalam aplikasi Plantsnap.

Alur penelitian dapat dilihat pada Gambar dibawah ini :

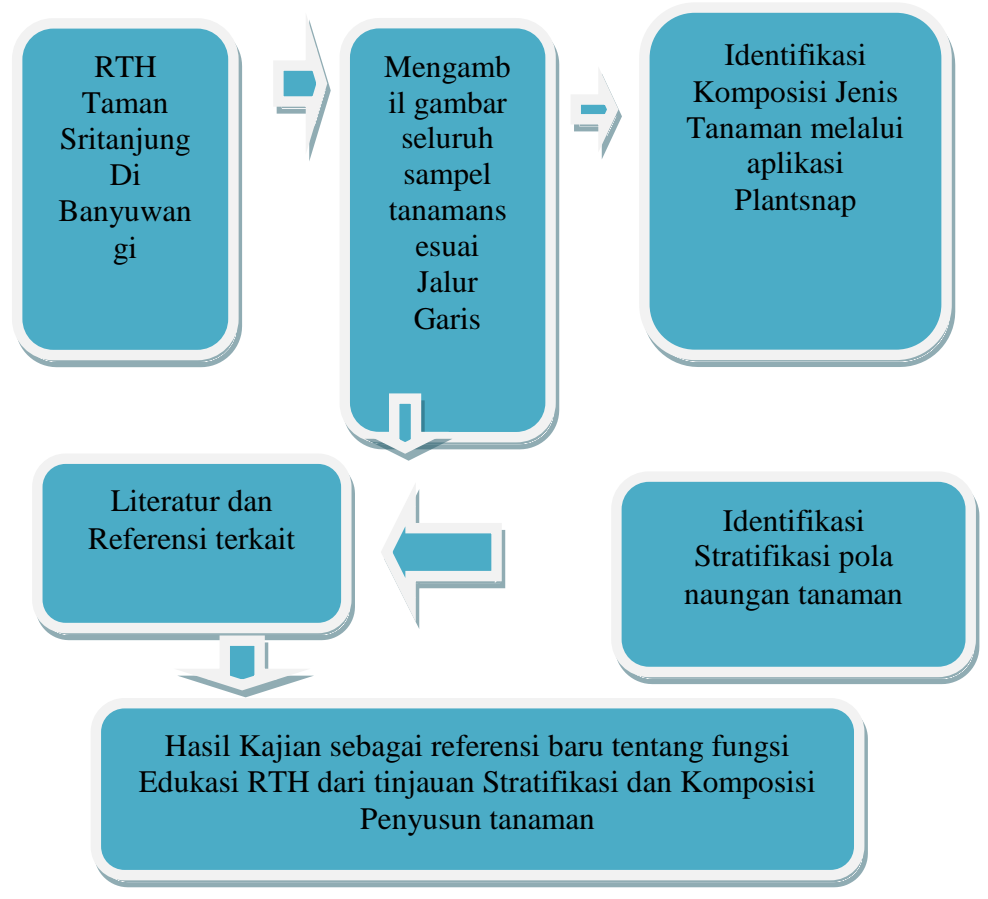

Gambar 1. Alur Pelaksanaan Penelitian

Data yang didapat dari hasil penelitian disajikan dalam bentuk tabel, selanjutnya dianalisis secara deskriptif kualitatif. Analisis deskriptif dimaksudkan untuk memberikan penjelasan dan uraian hubungan antar asatu faktor dengan faktor lain berdasarkan fakta, data dan informasi yang diperoleh selama penelitian lalu dijelaskan secara terperinci.

\section{III.HASIL DAN PEMBAHASAN}

Ruang Terbuka Hijau Taman Sritanjung Banyuwangi merupakan salah satu RTH yang ada di Banyuwangi yang diawali dengan kebutuhan Kota Banyuwangi terhadap suatu tempat yang dapat memberikan fungsi ekologi dan rekreatif kepada masyarakat setempat. RTH Taman Sritanjung Banyuwangi terletak di pusat kota tepatnya di depan Masjid Agung Baiturrahman dan di Pendopo Kabupaten Banyuwangi. Posisi RTH Taman Sritanjung Banyuwangi melalu foto Satelit dapat dilihat pada gambar 2. di bawah ini : 
Website : http://agritek.unmermadiun.ac.id/index.php/agritek

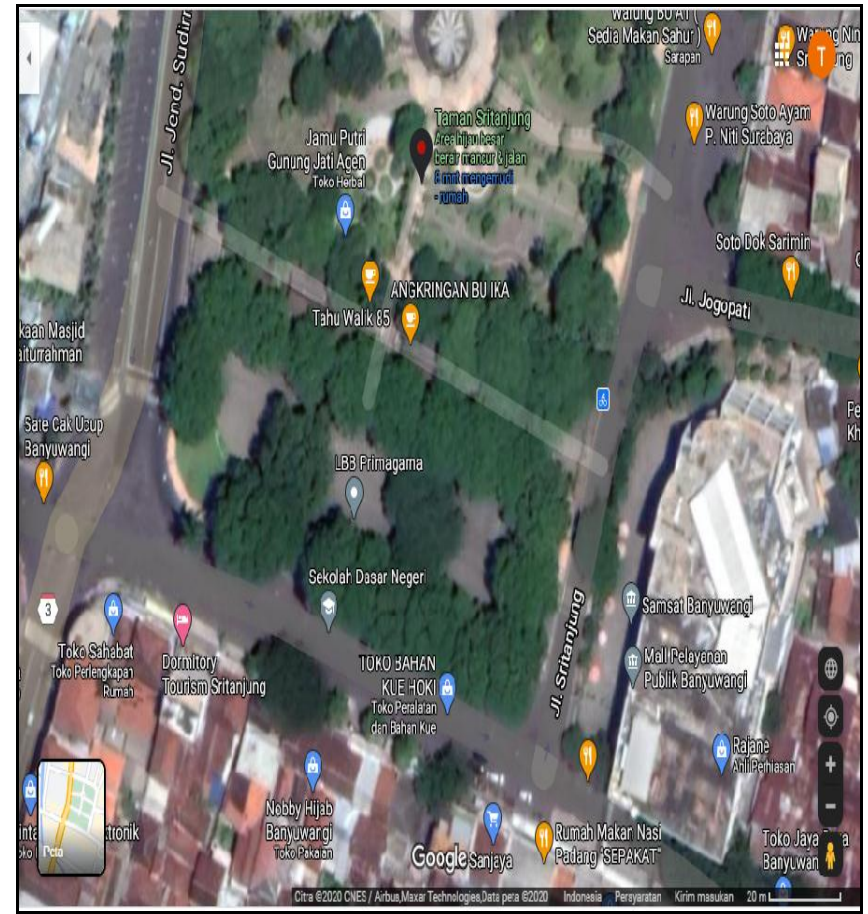

Gambar 2. Posisi RTH Taman Sritanjung di Kota Banyuwangi melalui Foto Satelit (CNES, 2020)

Dari gambar di atas nampak bahwa RTH Taman Sritanjung Banyuwangi memiliki letak strategis yakni di tengah perkotaan. Berfungsi ekologis, yakni sebagai pengatur keseimbangan lingkungan, sebagai paru-paru kota sumber oksigen dan penghijauan di sekitar pusat Kota Banyuwangi dan sekaligus fungsi rekreatif bagi masyarakat di tengah kota Banyuwangi.

Hasil pengamatan menunjukkan bahwa komposisi Jenis tanaman hortikultura yang dipilih sebagai penyusun taman di RTH Taman Sritanjung Banyuwangi terdiri atas 33 jenis tanaman. Keseluruhan jenis tanaman ini terbagi dalam berbagai jenis tegakan, yakni tegakan Pohon, semak dan tanaman penutup tanah (cover crops). Mengenai komposisi berbagai jenis tanaman pada RTH Sritanjung beserta nama ilmiah dan jumlah tanaman dapat dilihat pada Tabel 1. dibawah ini:

Tabel 1. Komposisi Jenis Tanaman Hortikultura Penyusun RTH Taman Sritanjung Banyuwangi

\begin{tabular}{|c|c|c|c|}
\hline No & Nama Umum & Nama Ilmiah & Jumlah \\
\hline 1 & Beringin & Ficus benjamina & 2 \\
\hline 2 & Sawo & Manilkara zapota & 4 \\
\hline 3 & Mahoni & $\begin{array}{l}\text { Swietenia } \\
\text { mahogani }\end{array}$ & 8 \\
\hline 4 & Trembesi & Samanea saman & 2 \\
\hline 5 & Ketapang & $\begin{array}{l}\text { Terminalia } \\
\text { catappa }\end{array}$ & 6 \\
\hline 6 & Cemara Lilin & $\begin{array}{l}\text { Cupressus } \\
\text { sempervirens }\end{array}$ & 6 \\
\hline 7 & Palem Raja & Roystonia regia & 24 \\
\hline 8 & Gebang & Corypha utan & 2 \\
\hline 9 & Dadap merah & $\begin{array}{l}\text { Erythrina crista- } \\
\text { galli }\end{array}$ & 2 \\
\hline 10 & Palem Botol & $\begin{array}{l}\text { Hyophorbe } \\
\text { lagenicaulis }\end{array}$ & 12 \\
\hline 11 & Bougenvill & Bougainvillea & 4 \\
\hline
\end{tabular}


Website : http://agritek.unmermadiun.ac.id/index.php/agritek

\begin{tabular}{|c|c|c|c|}
\hline & & gallabra & \\
\hline 12 & Bambu Jepang & $\begin{array}{l}\text { Pseudosasa } \\
\text { japonica }\end{array}$ & 30 \\
\hline 13 & Pucuk Merah & $\begin{array}{l}\text { Syzygium } \\
\text { paniculatum }\end{array}$ & 40 \\
\hline 14 & Puring & $\begin{array}{l}\text { Codiaeum } \\
\text { varigatum }\end{array}$ & 30 \\
\hline 15 & Waru & Hibiscus tilaecius & 2 \\
\hline 16 & Kiara Payung & Filicium decipiens & 4 \\
\hline 17 & Sikat Botol & $\begin{array}{l}\text { Callistemon } \\
\text { viminalis }\end{array}$ & 2 \\
\hline 18 & Tanjung & Mimusops elengi & 2 \\
\hline 19 & Pule & Alstonia scholaris & 2 \\
\hline 20 & Akasia & Acacia mangium & 4 \\
\hline 21 & $\begin{array}{l}\text { Glodokan } \\
\text { Tiang }\end{array}$ & $\begin{array}{l}\text { Polyalthia } \\
\text { longifolia }\end{array}$ & 20 \\
\hline 22 & Bungur & $\begin{array}{l}\text { Laegerstromia } \\
\text { speciosa }\end{array}$ & 4 \\
\hline 23 & Asoka & Saraca asoca & 32 \\
\hline 23 & Rembosa & $\begin{array}{l}\text { Tabernaemontana } \\
\text { corymbosa }\end{array}$ & 24 \\
\hline 24 & Lili Paris & $\begin{array}{l}\text { Chlorophytum } \\
\text { comosum }\end{array}$ & 120 \\
\hline 25 & Bunga Sepatu & $\begin{array}{l}\text { Hibiscus } \quad \text { rosa- } \\
\text { sinensis }\end{array}$ & 6 \\
\hline 26 & Sansievera & $\begin{array}{l}\text { Dracaena } \\
\text { trifasciata }\end{array}$ & 40 \\
\hline 27 & Hanjuang & $\begin{array}{l}\text { Cordyline } \\
\text { fruticosa }\end{array}$ & 40 \\
\hline 28 & Akalipa & $\begin{array}{l}\text { Acalypha } \\
\text { wilkesiana }\end{array}$ & 46 \\
\hline 29 & $\begin{array}{l}\text { Hingkip } \\
\text { mirten }\end{array}$ & $\begin{array}{l}\text { Serissa foetida } \\
\text { variegated }\end{array}$ & 200 \\
\hline 30 & Kucai mini & Carex morrowii & 250 \\
\hline 31 & $\begin{array}{l}\text { Bunga } \\
\text { Terompet }\end{array}$ & $\begin{array}{l}\text { Brugmansia } \\
\text { arborea }\end{array}$ & 8 \\
\hline 32 & $\begin{array}{l}\text { Rumput } \\
\text { Jepang }\end{array}$ & Zoysia japonica & 1000 \\
\hline 33 & Duranta & Duranta erecta & 400 \\
\hline
\end{tabular}

Dari data yang didapatkan, dapat dilihat bahwa tanaman hortikultura yang dipilih sebagai penyusun RTH Taman Sritanjung adalah $97 \%$ berasal dari jenis tanaman hias, sedangkan 3\% sisanya berasal dari tanaman buah yakni Tanaman Sawo (Manilkara zapota).

Komposisi tanaman hortikultura yang digunakan sebagai penyusun suatu Ruang Terbuka Hijau (RTH) juga disadasarkan berdasarkan fungsi dari masing masing jenis tanaman yang dipilih. Moersidik (2012) menyatakan bahwa Tanaman Hortikultura yang dipilih harus memiliki fungsi yang diharapkan yakni sebagai tanaman peneduh, tanaman penyerap polusi udara, tanaman penyerap kebisingan, tanaman pemecah angin, tanaman pembatas, pengarah dan pembentuk pandangan, tanaman konservasi dan tanaman penutup. Berdasarkan Data komposisi Jenis tanaman Hortikultura yang didapatkan di RTH Taman Sritanjung, maka dapat dideskripsikan pengelompokan jenis tanaman sesuai dengan fungsinya adalah sebagai berikut 
Website : http://agritek.unmermadiun.ac.id/index.php/agritek

1. Tanaman Peneduh merupakan jenis tanaman hortikultura yang ditempatkan pada jalur tanaman, memiliki daun yang rimbun dan memiliki percabangan $2 \mathrm{~m}$ diatas tanah, berasal dari perbanyakan biji dan tidak mudah tumbang (Ashari, 2006) . Jenis tanaman yang dipilih di RTH Sritanjung Banyuwangi adalah : Kiara Payung (Filicium decipiens), Bungur (Laegerstromia speciosa), Tanjung (Mimusops elengi), Ketapang (Terminalia catappa), Beringin (Ficus benjamina)

2. Tanaman Penyerap Polusi Udara merupakan jenis tanaman pohon atau perdu yang memiliki daun padat dengan jarak tanam rapat dan memiliki kemampuan untuk menyerap polusi udara (Ashari, 2006). Jenis tanaman yang dipilih di RTH Sritanjung Banyuwangi adalah Bougenville (Bougainvillea gallabra), Akasia (Acacia mangium), Lili Paris (Chlorophytum comosum) dan Sansievera (Dracaena trifasciata),

3. Tanaman Penyerap Kebisingan atau peredam suara merupakan jenis tanaman yang memiliki banyak daun rimbun dan padat, dan memiliki banyak tajuk percabangan (Anatari dan Sundra., 2002; Hidayat, 2010). Jenis tanaman yang dipilih di RTH Sritanjung Banyuwangi adalah Kiara Payung (Filicium decipiens), Kembang Sepatu (Hibiscus rosa-sinensis), Duranta (Duranta erecta) dan Waru (Hibiscus tilaecius)

4. Tanaman Pemecah Angin merupakan jenis tanaman yang yang memiliki tinggi lebih dari 3 meter, dengan percabangan yang padat. (Mukhlison, 2013). Jenis tanaman yang dipilih di RTH Sritanjung Banyuwangi adalah Cemara Lilin (Cupressus sempervirens), Mahoni (Swietania mahagoni), Glodokan Tiang (Polyalthia longifolia), Pule (Alstonia scholaris), Sikat Botol (Callistemon viminalis), Gebang (Corypha utan)

5. Tanaman Pembatas, Pengarah dan Pembentuk pandangan merupakan jenis tanaman yang ditanam di jalur jalan setapak, ditanam dengan jarak tanam rapat dan memiliki daun yang padat. (Mukhlison, 2013). Jenis tanaman yang dipilih di RTH Sritanjung Banyuwangi adalah Bambu Jepang (Pseudosasa japonica), Palem Botol (Hyophorbe lagenicaulis), Bunga Terompet (Brugmansia arborea), Sikat Botol (Callistemon viminalis), Pucuk Merah (Syzygium paniculatum), Dadap Merah (Erythrina crista-galli), Palem Raja (Roystonia regia)

6. Tanaman Konservasi dan penutup tanah merupakan jenis tanaman yang berfungsi untuk menutup permukaan tanah dengan perakaran yang meluas untuk menjaga tanah dari cekaman erosi (Ernawati, 2013). Jenis tanaman yang dipilih di RTH Sritanjung Banyuwangi adalah Asoka (Saraca asoca), Rembosa (Tabernaemontana corymbosa), Lili paris (Chlorophytum comosum), Akalipa (Acalypha wilkesiana), Hingkip mirten (Serissa foetida variegated), Kucai mini (Carex morrowii), Rumput jepang (Zoysia japonica) dan Duranta (Duranta erecta)

Menurut Arrijani (2006), ditinjau dari Stratifikasinya, tanaman hortikultura dikelompokkan menjadi empat kelompok, yakni (1) Emergent Layer, (2) Canopy Layer, (3) Lower Canopy, dan (4) Shrubs dan Ground Cover. Berdasarkan penelitian yang telah dilakukan di RTH Taman Sritanjung Banyuwangi maka Tanaman Hortikultura yang dipilih sebagai penyusun RTH Taman Sritanjung Banyuwangi dapat dikelompokkan berdasarkan Stratifikasinya pada tabel dibawah ini :

Tabel 2. Stratifikasi Tanaman Hortikultura di RTH Taman Sritanjung Banyuwangi

\begin{tabular}{|c|c|c|c|}
\hline No & Stratifikasi & Ciri tanaman & $\begin{array}{ll}\text { Nama } & \text { Ilmiah } \\
\text { Tanaman } & \\
\end{array}$ \\
\hline 1 & $\begin{array}{l}\text { Emergent } \\
\text { Layer }\end{array}$ & $\begin{array}{c}\text { Pohon } \\
\text { Tinggi } \\
\text { mencapai } 4 \\
\text { hingga } 20 \\
\text { meter } \\
\text { Percabangan } \\
\text { padat }\end{array}$ & $\begin{array}{l}\text { Ficus benjamina } \\
\text { Manilkara zapota } \\
\text { Swietenia mahogani } \\
\text { Samanea saman } \\
\text { Corypha utan } \\
\text { Mimusops elengi }\end{array}$ \\
\hline 2 & Canopy Layer & $\begin{array}{l}\text { Pohon } \\
\text { Tinggi } \\
\text { mencapai } 2 \\
\text { hingga } 4 \\
\text { meter } \\
\text { Percabangan } \\
\text { padat }\end{array}$ & $\begin{array}{l}\text { Terminalia catappa } \\
\text { Cupressus } \\
\text { sempervirens } \\
\text { Roystonia regia } \\
\text { Syzygium } \\
\text { paniculatum } \\
\text { Erythrina crista-galli } \\
\text { Filicium decipiens } \\
\text { Alstonia scholaris } \\
\text { Polyalthia longifolia } \\
\text { Laegerstromia } \\
\text { speciosa }\end{array}$ \\
\hline 3 & $\begin{array}{l}\text { Lower } \\
\text { Canopy }\end{array}$ & $\begin{array}{l}\text { Pohon } \\
\text { Tinggi } \\
\text { mencapai } \\
\text { hingga } \\
\text { meter }\end{array}$ & $\begin{array}{l}\text { Hyophorbe } \\
\text { lagenicaulis } \\
\text { Pseudosasa japonica } \\
\text { Codiaeum varigatum } \\
\text { Hibiscus tilaecius } \\
\text { Callistemon viminalis }\end{array}$ \\
\hline
\end{tabular}


Website : http://agritek.unmermadiun.ac.id/index.php/agritek

\begin{tabular}{|c|c|c|c|}
\hline & & $\begin{array}{l}\text { Percabangan } \\
\text { sedang hingga } \\
\text { padat }\end{array}$ & Brugmansia arborea \\
\hline \multirow[t]{4}{*}{4} & \multirow[t]{4}{*}{ Shrubs } & Semak & $\begin{array}{l}\text { Bougainvillea } \\
\text { gallabra }\end{array}$ \\
\hline & & $\begin{array}{l}\text { Tinggi } \\
\text { mencapai } \\
\text { meter }\end{array}$ & $\begin{array}{l}\text { Codiaeum varigatum } \\
\text { Saraca asoca } \\
\text { Tabernaemontana }\end{array}$ \\
\hline & & & $\begin{array}{l}\text { Hibiscus } \quad \text { rosa- } \\
\text { sinensis }\end{array}$ \\
\hline & & $\begin{array}{l}\text { Percabangan } \\
\text { padat }\end{array}$ & $\begin{array}{l}\text { Cordyline fruticosa } \\
\text { Acalypha wilkesiana } \\
\text { Duranta erecta }\end{array}$ \\
\hline
\end{tabular}

Dari Tabel 2. di atas dapat diketahui bahwa RTH Taman Sritanjung Banyuwangi merupakan salah satu Ruang Terbuka Hijau dengan penyusun tanaman hortikultura yang dipilih telah sesuai berdasarkan stratifikasinya. Keberadaan pohon Beringin (Ficus Benjamina) sebagai emergent layer mampu memberikan naungan yang teduh dan sejuk di bagian depan dan belakang RTH Taman Sritanjung. Pemilihan rumput jepang (Zoysia japonica) dan Hingkip Mirten (Serissa foetida variegated) sebagai Ground cover memberikan fungsi tambahan tanaman hortikultura sebagai fungsi ekologi agar terhindar dari cekaman erosi tanah. Penampakan RTH Taman Sritanjung bila ditinjau dari Stratifikasinya dapat dilihat pada gambar 2. dibawah ini :

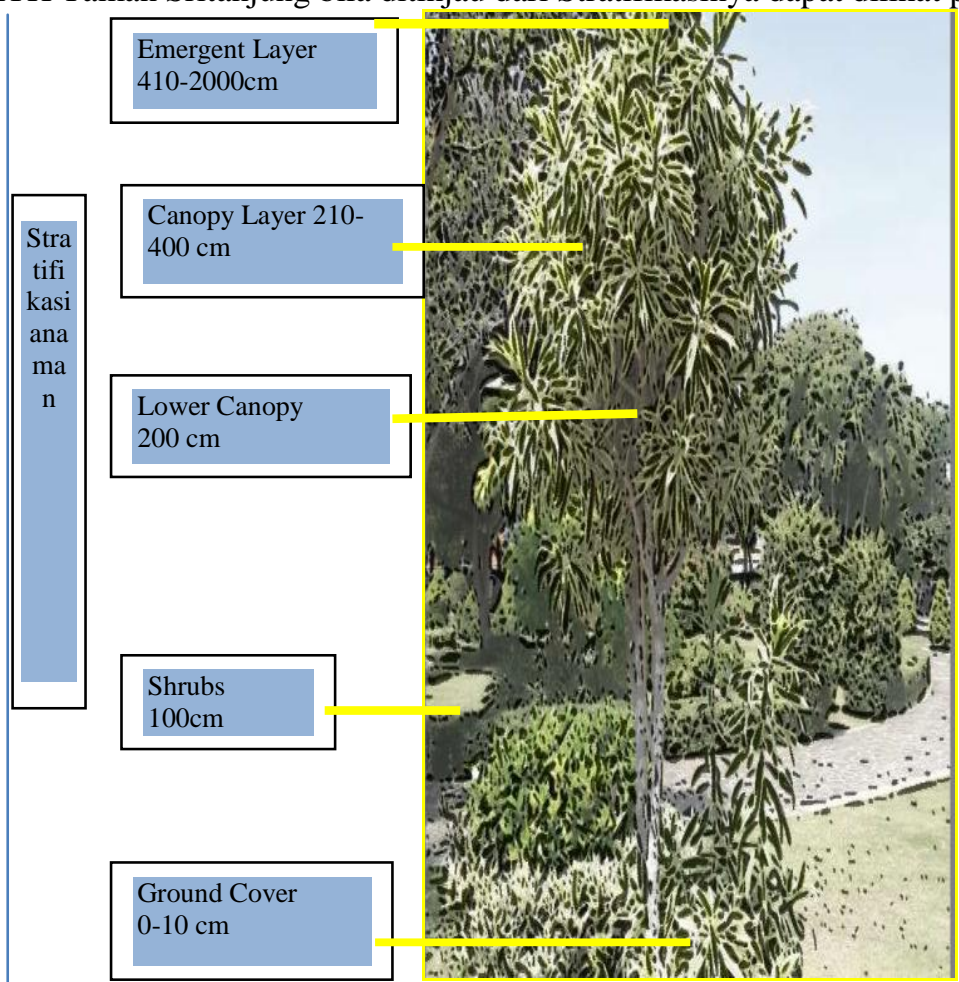

Gambar 2. Stratifikasi Tanaman Hortikultura di RTH Taman Sritanjung Banyuwangi

\section{IV.KESIMPULAN}

Dari hasil penelitian dan pembahasan dapat disimpulkan bahwa : (1) Dari aspek komposisinya, terdapat 33 Jenis tanaman Hortikultura yang terpilih sebagai penyusun RTH Taman Sritanjung Banyuwangi, yang dikelompokkan berdasarkan aspek fungsional tanaman, diantaranya tanaman peneduh, (5 jenis) tanaman penyerap polusi udara (4 jenis), tanaman penyerap kebisingan (4 jenis), tanaman pemecah angin (6 jenis), tanaman pembatas, pengarah dan pembentuk pandangan (7 jenis), tanaman konservasi dan tanaman penutup (8 jenis), (2) Ditinjau dari segi Stratifikasinya, maka tanaman hortikultura yang dipilih sebagai penyusun di RTH Sritanjung Banyuwangi dapat dikelompokkan menjadi Emergent Layer, Canopy Layer, Lower Canopy, Shrubs dan Ground Cover 
Website : http://agritek.unmermadiun.ac.id/index.php/agritek

\section{UCAPAN TERIMA KASIH}

Ucapan Terima kasih kami sampaikan kepada BAPPEDA Kabupaten Banyuwangi, Pengelola RTH Taman Sritanjung Banyuwangi, dan seluruh pihak yang ikut terlibat dan membantu dalam proses penyempurnaan penelitian ini.

\section{VI.DAFTAR PUSTAKA}

Arrijani. 2006. Model arsitektur pohon pada Hulu DAS Cianjur Zona SubMontana Taman Nasional gunung Gede Pangrango, Disertasi. Bogor: Institut Pertanian Bogor.

Antari AARJ dan Sundra IK. (2002). Kandungan Timah Hitam (Plumbum) Pada Tanaman Peneduh Jalan di Kota Denpasar. http://ejournal.unud. ac.id/abstrak/4.pdf. 15 Maret 2012.

Balai Penelitian Tanaman Hias. 2018. Acuan Standar Mutu Bunga Potong Krisan. Jakarta : Direktorat Budidaya Tanaman Hias

Bappeda. 2013. Rencana Tata Ruang Wilayah Kota Banyuwangi. Banyuwangikab.go.id

CNES. 2020. Satellite Image Gallery. Banyuwangikab.go.id

Ernawati, 2013. Komposisi Jenis dan Penggunaan Ekologi di Wilayah Desa Pangi Kawasan Cagar Alam Pangi Binangga Kabupatan Parigi Moutong. Vol 8, No 2

Hidayat, I.W. 2010. Kajian Fungsi Ekologi Jalur Hijau Jalan Sebagai Penyangga Roadside Greenery Os Environmental Bulfer On Jagorawi Highway). J.Manusia Dan Lingkungan. 17(2): 124 - 133.

Kaharudin. 2002. Laporan Penelitian: Studi Kesesuaian Jenis Vegetasi di Yogyakarta. Fakultas Kehutanan UGM. Yogyakarta.

Kershaw, 1973. Komponen Struktur Vegetasi Riparian. Pustaka Latin. Bogor.

Moersidik. 2012. Pembangunan Kota Hijau Berkelanjutan (Green City). Kick Off P2KH Wilayah Timur Direktorat Jenderal Penataan Ruang Kementerian Pekerjaan Umum.

Mukhlison. 2013. Pemilihan Jenis Pohon Untuk Pengembangan Hutan Kota Di Kawasan Perkotaan Yogyakarta. Jurnal Ilmu Kehutanan. VII(1): $37-47$

Purwantik, S., Sasmito B., dan Haniee ah. 2014. Analisis Ketersediaan Ruang Terbuka Hijau (RTH) Berdasarkan Kebutuhan Oksigen (Studi Kasus : Kota Salatiga). Jurnal Geodesi Undip. 3(3): 124-135.

Undang-undang Republik Indonesia. 2007. Penataan Ruang. Undang Undang Nomor 26 Tahun 2001. Jakarta. Sekretariat Negara. 